\title{
Early childhood safety education: an overview of safety curriculum and pedagogy in outer metropolitan, regional and rural NSW
}

\section{Article type}

Research Notes

\section{Abstract}

This article reports on preliminary findings from a 2008 survey and telephone interviews with 27 directors of early childhood education and care (ECEC) services located in regional and rural districts of the Australian state of New South Wales. Data from the study suggest that some areas of safety education-most notably $\mathrm{road} /$ traffic safety and fire safety-are well represented in early childhood curricula. However, areas such as water and farm safety are under-represented, despite statistics showing these to be significant areas of risk to young children. Findings suggest a need for a broader range of easily accessible and cost-effective childcentered teaching and learning safety education resources for use in ECEC settings.

\section{Background}

Childhood safety is an important concern, and learning to recognize and avoid potential hazards is broadly considered a necessary dimension of young children's formal and informal learning. This article reports on research conducted in early childhood education and care (ECEC) services located in regional and rural districts of south central New South Wales (NSW). The rationale for the study was based on a preliminary review of the literature showing that existing safety education research is primarily focused on: risk factors for specific types of accident/injury (fire, road, etc), often with emphasis on vulnerable groups (Dowswell \& Towner, 2002; Hendrickson, 2005; Mulvaney \& Kendrick, 2006); strategies for accident/injury prevention, including issues pertaining to teaching various aspects of safety (American Academy of Pediatrics, 2001; Cullen, 1995; Price, Murnan, Thompson, Dake, \& Telljohann, 2005; Tomlinson \& Sainsbury, 2004); and program or curriculum analyses or evaluations (Bruce \& McGrath, 2005; Cullen, 1995, 1998; Gatheridge et al., 2004; Utley et al., 2001). Less is known, however, about how pedagogic approaches, modes of delivery, social contexts and existing cultural practices impact on the effectiveness of safety education programs across different cohorts. While the area of road safety has, to date, received the most consistent attention by

TITLE: Early childhood safety education: an overview of safety curriculum 
education researchers, areas such as fire safety, water safety, home safety, farm safety, and community safety are as yet under-represented in the Australian educational research literature.

This research was conducted in early-mid 2008 as part of a larger project concerned with the development of safety education pedagogies and curricula across key domains of enquiry including fire safety, community safety, farm safety and home safety. The research is a scoping study that aims to map the range of safety education programs and resources that are currently in use in early childhood settings regionally, and to identify early childhood educators' perceptions of aspects of safety education that might be usefully developed for trial and implementation in the region. Here we report key findings pertaining to safety education themes that inform curriculum and pedagogies in participating ECEC centres.

\section{Methodology}

The mixed-method study utilized survey and informal interview methods, generating quantitative and qualitative data that maps current safety education practices, as well as areas of practitioners' perceived needs with regard to safety education resources. A purposive sample of twenty-seven (27) directors of early childhood and pre-school centres participated in a telephone survey and interview, with regional representations as depicted in Table 1 below:

\begin{tabular}{|l|c|}
\hline REGION & PARTICIPANTS \\
\hline Southern Highlands & 3 \\
\hline Central West & 8 \\
\hline Riverina & 6 \\
\hline Western Sydney & 7 \\
\hline Blue Mountains & 3 \\
\hline TOTAL & 27 \\
\hline
\end{tabular}

Table 1

The telephone survey, incorporated informal, semi-structured interview questions, and included standardized questions pertaining to specific programs, resources and

TITLE: Early childhood safety education: an overview of safety curriculum and pedagogy in outer metropolitan, regional and rural NSW SUBMISSION TO: Australian Journal of Early Childhood DATE: October 2008 
community services currently utilized for the purposes of teaching safety in the ECEC setting. Interview questions were open-ended, allowing for differences in the locations, clientele and operations of the centres surveyed. Interviews ranged from 10 minutes to 30 minutes in duration. Limitations of the study primarily related to the lack of time available for directors working within busy ECEC environments. This resulted in: numerous interruptions during some interviews with centre directors; insufficient time for checking details of requested information, such as names of particular suppliers of safety education resources that could not be immediately recalled; and, in some instances, directors declining to participate or becoming unavailable for participation due to time pressures and/or interruptions to scheduled interview appointments.

\section{Summary and discussion of key findings}

Key findings from the study can be summarized under four main themes, as illustrated in Table 2 below:

\begin{tabular}{|l|l|}
\hline \multicolumn{1}{|c|}{ THEMES } & \multicolumn{1}{c|}{ KEY FINDINGS } \\
\hline Regulatory environments & - Regulatory and accreditation requirements lead to \\
& privileging of institutional safety over children's \\
& safety education \\
& - Emphasis placed on evidence and audit procedures \\
- Potentially litigious environment leads to emphasis & on provision of information and advice to parents \\
\hline Financial constraints & - Due to budgetary constraints, most centres produce \\
& their own safety education resources using freely \\
& available online resources \\
& - Staff time spent in locating and developing safety \\
& resources represents additional human resource \\
& costs \\
& - High staff turn-over represents additional costs \\
& when resources developed by individual staff \\
& members do not remain centre property \\
\hline
\end{tabular}

TITLE: Early childhood safety education: an overview of safety curriculum 


\begin{tabular}{|c|c|}
\hline Curriculum \& pedagogy & $\begin{array}{l}\text { - Uneven availability and quality of safety education } \\
\text { resources suitable for use in ECEC settings } \\
\text { - Strong interest amongst directors in knowing more } \\
\text { about what resources are available and how they } \\
\text { are utilized elsewhere } \\
\text { - ECEC settings were best resourced in road, traffic } \\
\text { and/or vehicle safety, most notably through the } \\
\text { TRA/Macquarie University Kids and Traffic program; } \\
\text { These resources, in-services and communications } \\
\text { were generally held as an optimal standard for } \\
\text { government-industry partnerships in safety } \\
\text { education } \\
\text { - Centres were most poorly resourced in the areas of } \\
\text { farm safety and water safety, which had not been } \\
\text { considered a high priority in safety education } \\
\text { - Online resources are frequently utilized to make } \\
\text { posters and devise hands-on activities; commonly } \\
\text { used sites include the Google search engine and } \\
\text { www.Kidsafensw.org } \\
\text { - There is a perceived need amongst directors for a } \\
\text { greater range of effective, hands-on activities for } \\
\text { children, particularly in the areas of home, fire, farm } \\
\text { and water safety } \\
\text { - Preferences were expressed for taking a child- } \\
\text { centred, integrated approach to teaching about } \\
\text { safety, as opposed to regularly structured or } \\
\text { formalized programs }\end{array}$ \\
\hline $\begin{array}{l}\text { School - family } \\
\text { connections }\end{array}$ & $\begin{array}{l}\text { - Centres reported having significantly more materials } \\
\text { relating to safety information and advice for parents } \\
\text { than practical resources for educating children } \\
\text { about safety } \\
\text { - Some centres reported an active relationship with } \\
\text { parents through parent committees and regular } \\
\text { information sessions, however most centres drew } \\
\text { attention to the lack of parent interest and } \\
\text { participation in centre activities in what was } \\
\text { described as a one-way relationship of information } \\
\text { dissemination } \\
\text { - Parents working in safety-related professions, such } \\
\text { as police, fire or ambulance services, make valued } \\
\text { contributions to safety education through formal } \\
\text { visits and information sessions }\end{array}$ \\
\hline
\end{tabular}

TABLE 2

\section{Regulatory environments}

TITLE: Early childhood safety education: an overview of safety curriculum and pedagogy in outer metropolitan, regional and rural NSW SUBMISSION TO: Australian Journal of Early Childhood DATE: October 2008 
A key finding of this research pertains to the intensively regulated nature of ECEC services, and the extent to which the regulatory environment frames the conceptualization of and pedagogic approaches to safety education. The children's services sector is underpinned by a wide number of regulatory requirements under a two-tiered regulatory system consisting of the NSW Children's Services Regulation under the NSW Department of Community Services (DoCS), and the national Quality Improvement and Accreditation System (QIAS) under the National Childcare Accreditation Council (NCAC), and encompassing Occupational Health and Safety (OHS) requirements. Under the QIAS, Quality Area 5 outlines principles relating to protective care and safety as follows:

\section{Quality Area 5 - Protective Care and Safety}

- Principle 5.1: Staff act to protect each child

- Principle 5.2: Staff supervise children at all times

- Principle 5.3: Staff ensure that potentially dangerous products, plants and objects are inaccessible to children

- Principle 5.4: The centre ensures that buildings and equipment are safe

- Principle 5.5: The centre promotes occupational health and safety

(Source: NCAC: $\underline{\text { www.ncac.gov.au) }}$

What stands out in these principles is the emphasis on adult responsibility for ensuring the safety of children whilst in care. While we are in agreement with the importance of ensuring the safety of children in ECEC settings, we concur with policy critiques that raise concerns about the potential negative effects of over-regulation and the audit cultures to which it gives rise (Fenech, Sumsion, \& Goodfellow, 2008). As demonstrated in the principles listed above, and supported by the interview data from this study, the privileging of institutional safety over child safety results in prioritizing compliance with safety regulations within the ECEC centre, or educating staff about safety issues.

TITLE: Early childhood safety education: an overview of safety curriculum 
There is an expectation that ECEC centres will 'develop a culture of safety in the service' by staying 'up to date and aware of safety issues' which include providing 'advice and support to families for providing safe home environments for children' (QIAS Factsheet \#2). Quality procedures in Centres are monitored through a process of self-evaluation and external validation every two and a half years, supplemented since July 2006 by additional random spot checks by appointed NCAC Validators. Accreditation requires evidence that ongoing safety education is integrated into the curriculum, such as in the form of curriculum records, day book entries, photographs, records/displays of children's work and evaluative materials. While this expectation ensures the inclusion of safety education in some forms, participants in the study repeatedly emphasized the influence of the policy and regulatory environment on a climate in which safety in situ is typically prioritized over safety issues with broader applicability.

\section{Financial Constraints}

Budgetary considerations pose a major concern in the selection and use of resources. Many centres drew attention to the scarcity of resources for educating children compared with the amount of information directed towards parents. Also, commercially available materials were generally considered problematic. In the first instance, participants held most commercially produced resources as too expensive for centres' limited budgets. For example, one centre reported that the cost of a resource package they enquired about was $\$ 300$. Consequently, they developed their own materials drawing on information available on the program website. $A$ second concern expressed was that commercial resources were sometimes not relevant or appropriate for the centre's needs. As one Director observed:

Mass produced things often don't hit the mark. You pay a lot of money, but you end up making materials yourself from downloads from websites because you know exactly what you want.

TITLE: Early childhood safety education: an overview of safety curriculum and pedagogy in outer metropolitan, regional and rural NSW SUBMISSION TO: Australian Journal of Early Childhood DATE: October 2008 
This comment raises the important issue of staff time, given the widespread agreement across all the research sites concerning the considerable amounts of time spent by staff in ECEC centres in devising their own materials from the internet, posters and pamphlets they have received, as well as local sources including hospitals, council offices and community centres. The widespread reliance on webbased resources merits particular consideration here. Recent research evaluating the quality of online safety education resources (Isaac, Cusimano, Sherman, \& Chipman, 2004) contends that there is considerable variation in the suitability of safety-related information available online. Utilising independent reviewers to rate the content and quality of resources for teachers, parents and children, Isaac et al found that $74.5 \%$ of the 55 internet safety education resources did not meet sufficient criteria to merit being recommended for use.

Approximately $50 \%$ the Directors interviewed noted that their centre had over time developed folders of resources for safety education. However, an additional cost consideration affecting the quality and availability of safety education resources in ECEC settings pertains to questions of intellectual property and resource ownership. For example, one centre drew attention to the problem of intellectual property and high staff turnover, noting that staff who make up their own resources in their own time may take the resources with them when they left the centre. This raises questions about continuity of resource availability, particularly given that a significant proportion of online safety education resources are not available indefinitely (Isaac, Cusimano, Sherman, \& Chipman, 2004), posing additional difficulties for replacing resources that have been removed from the ECEC setting.

\section{Curriculum and pedagogy}

Approximately one third of the centres reported operating with a structured curriculum designed around weekly themes within which aspects of safety education could be discussed. The majority, however, reported operating on a more flexible basis with what one director called a 'child centred curriculum' that allowed content areas to arise depending on the children's particular interests, issues and local 
events. A number of safety education areas were structured around scheduled visits, such as the fire brigade, police, ambulance officers or health professionals, with preparation and follow-up activities, or incorporated into excursions, such as road safety in the walk to the local museum. Apart from scheduled visits and excursions, however, the nature and the degree of safety education being conducted at different centres is highly variable.

Almost all centres reported that their most comprehensive array of practical and useful resources in both fire and road, traffic and/or vehicle safety. All but two centres routinely obtain resources through the Road Traffic Authority (RTA)/Macquarie University (www.kidsandtraffic.mq.edu.au) program, whose inservices provide resource packs (both free of charge and some additional packages for purchase) including puzzles, posters, lotto games, story books with tapes, as well as brochures for distribution to parents. These resources were highly appraised by centres as the desired standard of resources for safety education. One centre in the outer west region of Sydney, with a very high number of NESB/EAL families, predominantly Indian, Chinese and Arabic, highlighted the need for road safety materials in home languages as it was felt that parents (or grandparents, who are often responsible for dropping off and collecting the children) did not always understand the rules relating to safety in the centre and its carpark (eg closing the gate and holding children's hands).

Notable areas of safety education that receive insufficient attention include farm and water safety. For example, despite drowning posing the single biggest risk to children under 5 (Kidsafe NSW), no centre participating in the study reported a water safety program. A number referred to policies of educating children about safe water play in the playground, and adhering to safety procedures such as water tubs being emptied while not in supervised use. Five centres reported that they discuss safety concerning swimming pools with the children during the summer months. Farm safety is similarly under-represented in the curriculum, despite the fact that "One

TITLE: Early childhood safety education: an overview of safety curriculum 
child dies on average every ten days in Australia through a farm-related incident" (Farmsafe Australia's "Child Safety On Farms Strategy" Launch by Federal Minister for Children and Youth Affairs:2002). No regional or rural centres reported an active program of farm safety in their curriculum, although a need for such resources was acknowledged. Centres serving children from farming families reported that farm safety issues were mostly addressed on an impromptu basis. For example, one director from a regional centre had initiated a session on snake safety after one child sighted a brown snake on their property. While there is considerable cross-over between farm safety and road safety (eg, riding in utes, wearing helmets) and water safety (eg, avoiding drowing in dams), a few directors from regional areas noted that road and water safety were always discussed in an urban context. One director wondered about the extent to which children would be able to relate such discussions to their own safety context on the farm.

\section{School-family connections}

Connections between parents and ECEC centres have a number of implications for safety education. ECEC centres often play an important role in the dissemination of safety related information and advice amongst parents and carers. Overall, centres participating in this study reported having considerably more information and resources intended for parents than practical resources for educating children about safety. Respondents were asked whether they or other staff received requests for information or learning resources from parents regarding particular areas of safety education. Participants largely responded in the negative, with one respondent replying, "quite the opposite!", reflecting the general consensus that safety education was a one-way process in which greater interest and involvement from parents would be welcomed by ECEC educators. As another director commented, "It's hard to get parents involved. It's generally drop-offs and pick-ups. They're generally busy with work".

TITLE: Early childhood safety education: an overview of safety curriculum and pedagogy in outer metropolitan, regional and rural NSW SUBMISSION TO: Australian Journal of Early Childhood DATE: October 2008 
A number of participants voiced deficit views of parents' interest in and/or practices relating to their children's safety. Approximately $25 \%$ of directors expressed concern that the degree of attention to safety within the centre was not shared by parents and carers, with the main gate marking a distinct spatial boundary between centre and parent responsibilities. Examples provided ranged from parents forgetting to close the gates, allowing children to sit in the front seat of cars, smoking in cars with passenger children and not being strict about holding hands with an adult. While a detailed analysis of this dimension of school-family connections is not possible here, it is worth noting their significance to the ways in which safety information is communicated and acted upon. These views notwithstanding, there were examples of parents requesting the support of centre staff in reinforcing safety principles that parents were endeavouring to teach their children. For example, one outer metropolitan centre noted a request from a parent that the staff reinforce the need to wear a seatbelt and hold hands with a parent/carer in public places. Another regional centre reported a parental request that the children receive a safety session on matches after their child was found at home with a box of matches, while another regional centre reported a request regarding teaching children about the dangers of running onto roads.

Under QIAS regulations, centres are required to provide child safety information and advice to families that is up to date and recognized by health and safety authorities (QIAS Factsheet \#2). Directors drew attention to the extensive amount of health and safety information provided to parents in the form of: pamphlets put in children's bags and/or parents' pigeonholes; information, pamphlets and posters in the centre foyers; information and advice included in newsletters or provided in parent information evenings at the centre. Parent participation also occurs through reading the day book to see what activities and information their child has been presented with each day. Three centres also reported that they send out a survey form every year seeking input from parents regarding suggestions for inclusion of particular safety advice, and inviting parents whose work may be interesting and relevant to

TITLE: Early childhood safety education: an overview of safety curriculum 
schedule a visit to the centre. As one centre director reported "That's how we got a police officer, a fire officer and someone from child protection".

\section{Conclusions}

This study suggests a need for further research investigating factors affecting the delivery of high quality safety education resources and programs in ECEC settings. Given the extent to which ECEC staff are obliged to research and source curricular materials, there is a need to assess staff development requirements for undertaking this important aspect of their professional practice. There is also a need for a broader and more widely implemented range of resources accessible, cost-effective, hands-on resources addressing those aspects of safety education that are currently under-represented in ECEC settings. In particular, given the significant risks of serious injury or death posed to children by drowning and farm accidents, water and farm safety would seem to merit considerably greater attention.

TITLE: Early childhood safety education: an overview of safety curriculum 


\section{References}

American Academy of Pediatrics. (2001). Prevention of Agricultural Injuries Among Children and Adolescents. Pediatrics, 108(4), 1016.

Bruce, B., \& McGrath, P. (2005). Group interventions for the prevention of injuries in young children: a systematic review. Injury Prevention, 11, 143-147.

Cullen, J. (1995). Road safety education at preschool: a reflective dialogue approach. Australian Research in Early Childhood Education, 1, 40-50.

Cullen, J. (1998). Influences on young children's knowledge: the case of road safety education. International Journal of Early Years Education, 6(1), 39-48.

Dowswell, T., \& Towner, E. (2002). Social deprivation and the prevention of unintentional injury in childhood: a systematic review. Health Education Research, 17(2), 221-237.

Fenech, M., Sumsion, J., \& Goodfellow, J. (2008). Regulation and risk: early childhood education and care services as sites where the 'laugh of Foucault' resounds. Journal of Education Policy, 23(1), 35 - 48.

Gatheridge, B. J., Miltenberger, R. G., Huneke, D. F., Satterlund, M. J., Mattern, A. R., Johnson, B. M., et al. (2004). Comparison of Two Programs to Teach Firearm Injury Prevention Skills to 6- and 7-Year-Old Children. Pediatrics, 114(3), e294e299.

Hendrickson, S. G. (2005). Reaching an underserved population with a randomly assigned home safety intervention. Injury Prevention, 11, 313-317.

Isaac, D., Cusimano, M. D., Sherman, A., \& Chipman, M. (2004). Child safety education and the world wide web: an evaluation of the content and quality of online resources. Injury Prevention, 10, 59-61.

Mulvaney, C., \& Kendrick, D. (2006). Do maternal depressive symptoms, stress and a lack of social support influence whether mothers living in deprived circumstances adopt safety practices for the prevention of childhood injury? Child: Care, Health \& Development, 32(3), 311-319.

Price, J., Murnan, J., Thompson, A., Dake, J., \& Telljohann, S. (2005). Elementary school teachers' involvement in firearm safety education. Journal of School Health, 75(3), 105-111.

Tomlinson, R., \& Sainsbury, C. (2004). Childhood injury prevention advice: a survey of health professionals responses to common scenarios. Child: Care, Health \& Development, 30(4), 301-305.

Utley, C., Reddy, S., Delquadri, J., Greenwood, C., Mortweet, S., \& Bowman, V. (2001). ClassWide peer tutoring: an effective teaching procedure for facilitating the acquisition of health education and safety facts with students with developmental disabilities. Education and Treatment of Children, 24(1), 1-27.

TITLE: Early childhood safety education: an overview of safety curriculum and pedagogy in outer metropolitan, regional and rural NSW SUBMISSION TO: Australian Journal of Early Childhood DATE: October 2008 